\title{
SELF-EFFICACY AND EXPECTANCY OF ENGINEERING STUDENTS IN HIGHER EDUCATION: A CASE STUDY OF THE PERCEPTIONS AND BELIEFS OF LECTURERS
}

\author{
K. Brown ${ }^{1}$, V. Lally ${ }^{2}$ \\ ${ }^{1}$ Letterkenny Institute of Technology (IRELAND) \\ ${ }^{2}$ University of Glasgow (UNITED KINGDOM)
}

\begin{abstract}
Online assessment is intended to enhance the learning experiences of students and improve the manner in which feedback is delivered. This paper reports on an international project, in three countries, to examine the beliefs of self-efficacy, and constructs of expectancy, held by engineering mathematics lecturers, and provides a comparison with those beliefs held by students, in the first year of undergraduate Bachelor of Engineering programmes. The interviews were semi-structured to stimulate conversations around a set of pre-determined themes. The thematic inputs to the lecturer interviews resulted from interpretative phenomenological analysis of the beliefs, experiences and perceptions of 127 students, gained from a series of questionnaires, and interviews. The aims of the engineering mathematics lecturer interviews were to examine current practices in terms of assessment of mathematics, and the provision of feedback, in both online and face-to-face formats, with a view to determining if the self-efficacy of students is a considered within the process. The research highlights differences in understanding of the assessment process held by lecturers, and students particularly in the early stages of the first semester. Evidence that students' meta-cognitive functions evolve over the first year of study to minimize the differences is provided. The implications of these findings are discussed.
\end{abstract}

Keywords: Assessment, mathematics, self-efficacy, expectancy.

\section{INTRODUCTION}

A smooth transition, from second level education to third level, is an efficacious desire of higher education institutions and the transitional period in year 1 is identified as an important stage [1] in the educational pathway. The transition to third level is recognised as being a period of major upheaval and considerable challenge for many university students [2,3]. These issues are reflected in retention rates and throughput rates to the second year of study. The educational pathway has been extended beyond traditional classroom, and face-to-face, learning to include [4] online learning and the assessment of learning by online technologies. Increasingly, within this process, the students are expected to engage in a greater degree of autonomous and self-directed learning. The resultant paradigm in higher education requires, strategies, policies, and actors, to be cognizant of the phase shift in expectations placed by them on students.

The self-directed learner is expected to engage, actively, [5] through self-discipline and motivation. Self-direction requires metacognitive capabilities in order to generate success, particularly in areas of problem solving. Students [6] from higher academic tracks perform well compared to those from lower academic tracks because they have better cognitive and better metacognitive strategies.

This study focuses on students from lower academic tracks and considers issues relating to those students. In this sense the socio-cognitive environment, of the cognitive apprenticeship engaged in by the learners, is crucial to the amplification of the achiever's metacognition and cognitive behaviours. In addition to the issues encountered whilst engaging and coping with the transitional phase, there is the added difficulty of engagement with Science, Technology, Engineering and Mathematics (STEM) [7]. Third level lecturers report that students are not sufficiently prepared to cope with STEM subjects at third level and this is an area of great concern. There is also evidence that negative attributes may be deeply embedded $[8,9]$ resulting in greater support requirements at third level.

The research designed within a social-cognitive theoretical framework of self-efficacy $[4,10]$ and expectancy [11], has been conducted primarily with first year engineering students in the School of Engineering in Letterkenny Institute of Technology (Ireland). Mathematics is a compulsory subject for all first year engineering students, in both semesters, offering exposure to traditional, face-to-face and 
online learning pedagogies. The student cohort available to the researchers engages in traditional face-to-face lectures, small group tutorials, hand-written assessments and online assessments; support material is available via a Learning Management System.

\subsection{Objectives}

The main objective of the research is to improve the educational experiences of first year students in the School of Engineering. Thus, the aims of the study are:

- To investigate the preconceptions learners bring to third level engineering.

- To investigate the levels of self-efficacy and determine potential barriers to engagement that learners may have using online assessment systems.

- To investigate the preconceptions instructors may have in third level engineering programmes.

\section{METHODOLOGY}

A two-year longitudinal study commenced with a pilot study in the second semester of academic year 2014/15. A mixed methods approach of enquiry was deployed, to determine indicative outputs from the pilot study, for the purpose of guiding and testing the research questions. The research was conducted and bounded within the shared mathematics domain of the first year of several Bachelor of Engineering programmes and separated into two sections; students and lecturers.

\subsection{Student Groups}

The methodology was explained to the students, after participation consent was sought, to ensure that all students were aware that any decision to participate or withdraw would not have any negative impact on them. Data was collected in week four of the first semester by means of an anonymized questionnaire, containing closed and open questions, within the class environment to maintain a structured contextual setting. The mixed-methods questionnaire contained two open questions, three dichotomous questions, and eight six-point Likert scale questions. An Interpretative Phenomenological Analysis [12] of the open responses was conducted to determine the main themes of the student responses. Analysis was conducted at the level of an utterance, which may be a statement, sentence or paragraph, and coded accordingly. The utterance code remained until a change in subtheme/theme was detected. All responses were coded for analysis and processing using SPSS.

To ensure synchronic reliability a sample of students was selected for a semi-structured group interview using standardized open-ended questioning, within two weeks of the thematic analysis, to explore the main thematic outputs in greater depth. All students were asked the same questions during the group interviews to ensure response comparability. The students were not self-selecting for this interview due to sampling being based on convenience of students to the researcher within a standard timetabled session.

A second interview was scheduled to make enquiry of a self-selecting group of students in second year of their study at the end of the third semester. The purpose of the group interview of second year students was to determine if a change in narrative had occurred or if the thematic issues of the first year students remained.

The same procedures and practices were followed for year two of the study to ensure triangulation and comparability of data between years.

\subsection{Lecturers}

Lecturers with experience of teaching engineering mathematics were invited to participate in semistructured individual interviews. The schedule of interviews for lecturers occurred over an academic year based on availability. The semi-structured questions were formed around the thematic areas of, student confidence, barriers, training and preparation, for online assessment. The interviews were extended outside Letterkenny Institute of Technology to include engineering mathematics lecturers from a University of Applied Sciences in Finland and a university in Northern Ireland. A coding schema was developed from the responses to the interviews with the unit of analysis being complete responses/phrases to reduce complexity. All responses were coded for analysis and processing using SPSS. 
A rigorous process of ethical scrutiny was engaged in prior to commencement of the study.

\section{RESULTS}

Prior to the thematic analysis of the lecturer interviews, a confirmatory process of thematic analysis of student responses was conducted to document that the students' thematic outputs were valid (Four major factors emerged: Confidence, Feedback, Self-efficacy and Expectancy).

Self-efficacy belief relates to the capability level and the strength of belief in that capability to reach a goal, i.e. the belief that one has the power to produce the required effect by completing a task or activity. Confidence in relation to self-efficacy has interesting connotations in that a person with high self-efficacy may participate poorly at a particular activity due to misplaced confidence and vice-versa. Confidence in this sense is difficult to define and varies according to the context in which it is examined. Expectancy describes the behavioural processes involved in selecting particular behavioural options in achieving a reward, task, or goal.

A total of 262 students participated in the study questionnaire (male, $n=254$; female, $n=8$ ). Analysis of gender related issues are not possible because of the low numbers of females studying the engineering programmes within this research. Group interviews of students were conducted with a total of 48 students participating in these interviews. All students were asked in the questionnaire to indicate if they had participated in any form of computer based testing in advance of their third level programme; $69.1 \%$ had prior experience however, $32.8 \%$ noted a negative experience whilst $84.2 \%$ of this group indicated that they were moderately confident or higher whilst engaging with those tests. Overall, $33.4 \%$ of utterances by students in the Interviews related to confidence - both negative and positive utterances (see Figure 1.). The level of confidence utterances dropped slightly to $31.7 \%$ in year 2 but the proportion of negative confidence comments increased to $70 \%$ and was closely related to issues of feedback.

Effective feedback to students is considered to be a central tenet of the assessment process with the potential to, foster improvement of student performance, build confidence and, aid retention. Analysis of comments by first year students reveals that only $5.22 \%$ of their comments are related to feedback. The percentage of comments relating to feedback rises to $18.5 \%$ by the end of semester 3 in the second year of study.

[S6_Y2, Dec 2016] "But there is no feedback and so we don't really know where we are going wrong or where we got it right"

[S5_Y2, Dec 2016] "There are no comments that come back after the test. You get your percentage back and that's it"

[S4_Y2, Dec 2016] "I preferred first year, you got your feedback and were able to move on"

Analysis of the thematic discussions with lecturers reveals that lecturers only mentioned feedback $5.8 \%$ of the time whilst discussing assessment. The comment by Student6_Y2 is not invalid when the thematic outputs of the lecturers are analysed.

\section{[L9, 2016] "I didn't really give feedback. It was just a mark allocated" \\ [L1, 2015] "I cannot get around all my students"}

When questioned on matters of student confidence, the utterances by seven lecturers indicated that they felt students did not have any problems with confidence and were not concerned. Two lecturers expressed awareness of issues of lack of confidence in mathematics.

$[L 7,2016] \quad$ "Many students listen in the background or send private messages because they may be less confident.

[L8, 2016] "The big thing I am trying to get over is their fear of maths"

Analysis of utterances where the thematic output was self-efficacy revealed that $56.2 \%$ of the utterances were positive in nature in the first semester mathematics (see Figure 2.). A domain of interest is that of expectancy, and in particular, the relationship between instrumentality and valence. The students' position is that of trust relating to analysis of their performance by lecturers; core to expectation. The perceived valence, or value, the student places on the outcome is a source of motivation and may affect self-efficacy. $72 \%$ of utterances by first year students related to feelings of 
negative expectancy. The majority of these utterances are directly attributable to the design of the online assessment system and the lack of partial credit in grading.

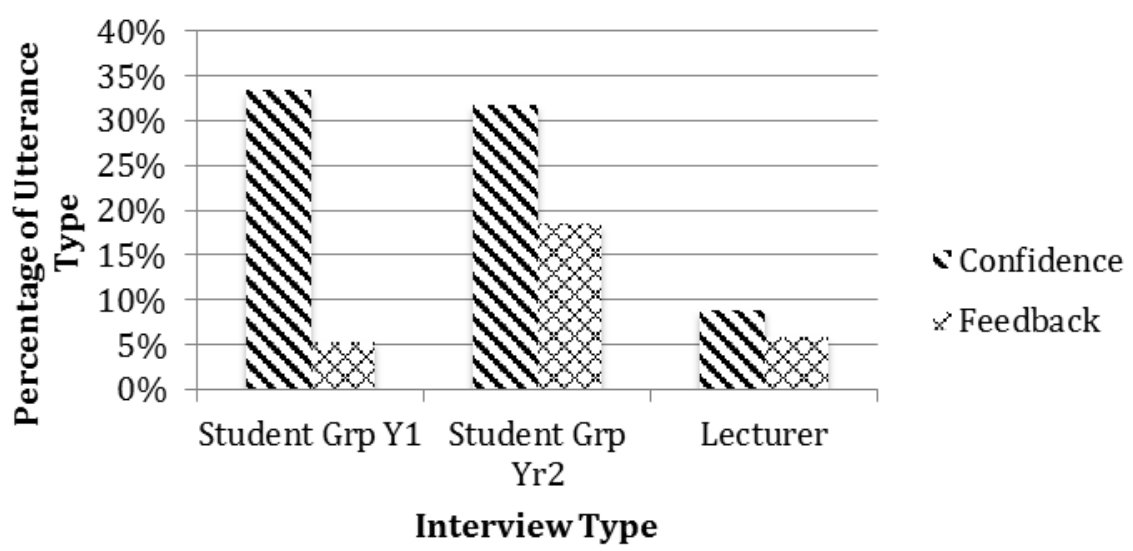

Figure 1. Histogram of percentage confidence and feedback utterances per interview type.

[S4_E_Y1, 2016] "You can still do the work and type something in wrong. You get marked wrong and get no marks for the work. Be nice to get some credit for your work"

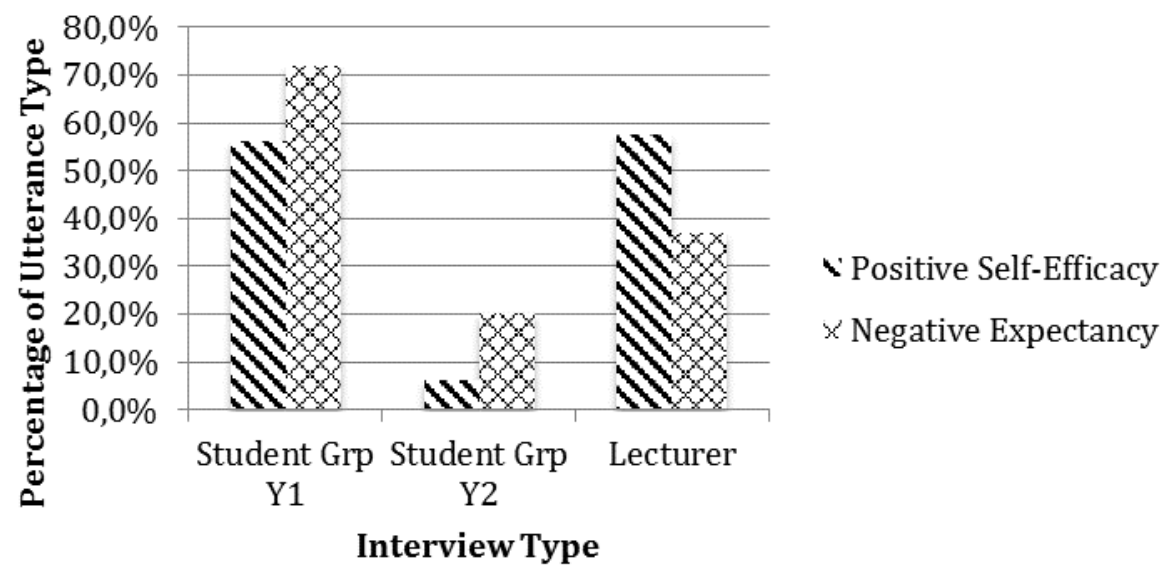

Figure 2. Histogram of Positive Self-Efficacy and Negative Expectancy Utterances.

Positive self-efficacy drops to $6.1 \%$ and negative expectancy drops to $20.3 \%$ and confidence accounts for $31.7 \%$ of utterances in year 2 . Analysis reveals that students are concerned about a relative reduction in feedback within the mathematics programme in year 2 in comparison with year $1.57 .7 \%$ of utterances by lecturers in relation to their perceptions of self-efficacy in students are positive. $37 \%$ of utterances in relation to expectancy are negative i.e. there is a belief that students do not consider that their performance is valued.

[L2, 2015] "They are picking things that are worth the effort rather than practicing their learning"

$[L 2,2015]$ "I find some have a very poor self-image when it comes to maths. There is a history of 'I am no good at maths!"”

$[L 9,2016]$ "Hopefully they will get into the way of it after a while, and they will maybe lose those fears".

\section{CONCLUSIONS}

Investigating the preconceptions, values placed on assessment, and self-efficacy, of students in their first year studying at third level education is challenging. The majority of the students are males and do not easily describe or express emotions openly. The study was designed to operate in a nonthreatening manner to maximise the potential for exploration of thoughts and reflections of both students and lecturers. This design aim was met through open dialogue with both sets of participants. 
Evidence gathered through questionnaires and interviews revealed considerable ranges of preconceptions held by first year students and these were considered to be affecting their self-efficacy in relation to mathematics. The vocabulary utilised by many students demonstrates a lack of awareness of the assessment processes at third level. The lack of awareness is evidenced through the changing narrative as first year students they move into second year and their vocabulary expands. As students become more aware of the assessment processes their emotions adapt to the changes. Self-efficacy and expectancy of the students appear to be determined by the assessment environment; if students do not see value in their performance, their own sense of worth may be affected leading to affirmation of negative behavioural attributes. The role of the lecturers in assessment is critical and their actions directly impact on the students. There may be a view by students that, what the lecturers consider to be important is not shared; particularly in first year programmes. Lecturers are aware of the need for feedback and support and yet they fail to mention feedback in any substantive form [13].

This study represents the findings from a two-year longitudinal study to gather an accurate reflection of the first year experience. The longitudinal study is necessary to reduce the effects of any anomalies in the data. The results will feed into the design processes of the first year mathematics programme to improve the student experience.

\section{REFERENCES}

[1] Y1 feedback (2016). Technology-Enabled Feedback in the First Year: A Synthesis of the Literature. Available from y1feedback.ie [accessed online 19 Sept 2016].

[2] Artino, A.R. \& Jones, K.D., (2012). Exploring the complex relations between achievement emotions and self-regulated learning behaviors in online learning, The Internet and Higher Education, 15(3), pp. 170-5.

[3] Van Rooij, E., Jansen, E., \& Van de Grift, W., (2016). Ready for University? Profiling Secondary School Students on University Readiness, ECER Conference, UCD, Dublin, 23 - 26 Aug 2016.

[4] Artino, A.R., (2012). Academic self-efficacy: from educational theory to instructional practice, Perspectives on medical education, 1(2), pp. 76-85.

[5] Robles, M. \& Braathen, S., (2002). Online assessment techniques, Delta Pi Epsilon Journal, 44(1), pp. $39-50$.

[6] Schneider, W. \& Artelt, C., (2010). Metacognition and mathematics education, ZDM, 42(2), pp. 149-61.

[7] McCraith, B., (2015). Average is no longer good enough - it's time for a step change in STEM education in Ireland, in Education Matters, Yearbook 2016 - 2016, pp. 13-18.

[8] Gallimore, M. \& Stewart, J., (2014). Increasing the impact of mathematics support on aiding student transition in higher education, Teaching Mathematics and its Applications, 33(2), pp. 98109.

[9] Tempel, T. \& Neumann, R., (2014). Stereotype threat, test anxiety, and mathematics performance, Social Psychology of Education, 17(3), pp. 491-501.

[10] Bandura, A., (1977). Self-efficacy: Toward a Unifying Theory of Behavioral Change, Psychological Review, 84(2), pp. 191-215.

[11] Vroom, V. H., Deci, E.L., (1970). Management and Motivation. Penguin 1983 (first published 1970).

[12] Smith, J.A., Flowers, P., \& Larkin, M., (2009). Interpretative Phenomenological Analysis, Computers in Human Behavior, 51, pp. 539 - 545.

[13] Veenman, M.V.J., Van Hout-Wolters, B.H.A.M. \& Afflerbach, P., (2006). Metacognition and learning: conceptual and methodological considerations, Metacognition and Learning, 1(1), pp. 3-14. 